\title{
Ensemble flood forecasting based on ensemble NWP and the GMKHM distributed hydrological model
}

\author{
Lili Wang, Hongjun Bao \\ National Meteorological Center, China Meteorological Administration, Beijing, 100081, P. R. China
}

\begin{abstract}
The incorporation of numerical weather predictions (NWP) into a flood forecasting system can increase forecast lead times from a few hours to a few days. A single NWP forecast from a single forecast centre, however, is insufficient as it involves considerable non-predictable uncertainties and lead to a high number of false alarms. The availability of global ensemble numerical weather prediction systems through the THORPEX Interactive Grand Global Ensemble' (TIGGE) offers a new opportunity for flood forecast. The GMKHM distributed hydrological model, which is based on a mixed runoff generation model and overland flow routing model based on kinematic wave theory, and the topographical information of each grid cell extracted from the Digital Elevation Model (DEM), is coupled with ensemble weather predictions based on the TIGGE database (CMC, CMA,ECWMF,UKMO,NCEP) for flood forecast. This paper presents a case study using the coupled flood forecasting model on the Xixian catchment (a drainage area of 8826 $\mathrm{km}^{2}$ ) located in Henan province, China. A probabilistic discharge is provided as the end product of flood forecast. Results show that the association of the GMKHM model and the TIGGE database gives a promising tool for the anticipation of flood events several days ahead,, comparable with that driven by raingauge observation.
\end{abstract}

\section{Introduction}

Flood protection and awareness have continued to rise on the political agenda accompanied by a drive to "improve" flood forecasts (Demeritt et al., 2007; DKKV, 2004; Parker and Fordham, 1996; Pitt, 2007; van Berkom et al., 2007; Cloke and Pappenberger, 2009). Giving flood forecasting services, civil protection authorities and the public adequate preparation time and thus reducing the impacts of the flooding (Penning-Rowsell et al., 2000). Many flood forecasting models rely on precipitation inputs, which come initially from observation networks (rain gauges) and radar.

Actually, the incorporation of numerical weather prediction (NWP) into a flood forecasting model can increase forecast lead times from a few hours to a few days. Single deterministic weather forecast from NWP can't take uncertainties and systematic biases into consideration and hence often fail to replicate weather variables correctly. Ensemble Prediction Systems (EPS) have evolved over the last decade to simulate the effect on weather forecasts of observation uncertainties, model uncertainties (e.g. due to a lack of resolution, simplified parameterization of physical processes and effect of unresolved processes), imperfect boundary conditions and data assimilation assumptions (Park et al., 2007). An EPS is interpreted by Buizza as a system based on a finite number of deterministic integrations and regarded as, so far, the only feasible method in meteorology to predict probability density function beyond the range of linear error growth. EPS forecasts from a single weather centre only account for part of the uncertainties originating from initial conditions and stochastic physics (Roulin, 2006). Other sources of uncertainties, including numerical implementations and/or data assimilation, can only be assessed if a grand ensemble (GE) of EPS from different weather centres are combined (Goswami et al., 2007). When various models that produce EPS from different weather centres are aggregated, the probabilistic nature of the ensemble precipitation forecasts is better retained and accounted for (He et al., 2009, 2010; Bao,2009;Bao and Zhao, 2012). An ensemble of weather forecasts can be used on catchment hydrology and provide improved early flood forecasting as some of the uncertainties can be quantified (Cloke and Pappenberger, 2008).

To this end, a case study was carried out using five TIGGE forecast centres. The GMKHM model (Bao et al. 2017a,2017b) was used to simulate the discharge. The study area is the Xixian catchment, located upstream of the Huaihe River. The aims of this paper are to (1) develop atmospheric-hydrologic flood forecasting model cascade driven by TIGGE ensemble forecasts, and (2) apply the model cascade to the Xixian catchment and compare the simulation results driven by TIGGE forecasts and raingauge observation.

*Correspondence to: Hongjun Bao (baohongjun@cma.gov.cn) 


\section{Case study area and Data}

The Huaihe River is located between latitudes $31^{\circ} \mathrm{N}$ and $35^{\circ} \mathrm{N}$ and longitudes $112^{\circ} \mathrm{E}$ and $121^{\circ} \mathrm{E}$. It originates in the Tongbai Mountains of Henan Province, and flows over four provinces in east-central China. The length of the main channel of the Huaihe River is $1000 \mathrm{~km}$ and the total catchment area is $1.912 \times 10^{5} \mathrm{~km}^{2}$. Its mean annual precipitation and runoff depth is approximately 888 and $240 \mathrm{~mm}$ respectively. The runoff coefficient ranges from 0.1 (northeast) to 0.6 (southwest). The Xixian catchment, located between latitudes $31.5^{\circ} \mathrm{N}$ and $33.0^{\circ} \mathrm{N}$ and longitudes $113.0^{\circ} \mathrm{E}$ and $115.0^{\circ} \mathrm{E}$ in the upstream of the Huaihe River, has a drainage area of $8826 \mathrm{~km}^{2}$ and is situated in the south of Henan province, China. The catchment average annual precipitation is $1145 \mathrm{~mm}, 50 \%$ of which is within the period of the flood season (JuneSeptember). Ten rainfall stations and one hydrological station are available in the Xixian catchment. Fig. 1 shows the location of Xixian catchment in China and the sketch of the upper reaches of Huaihe River above Xixian station.
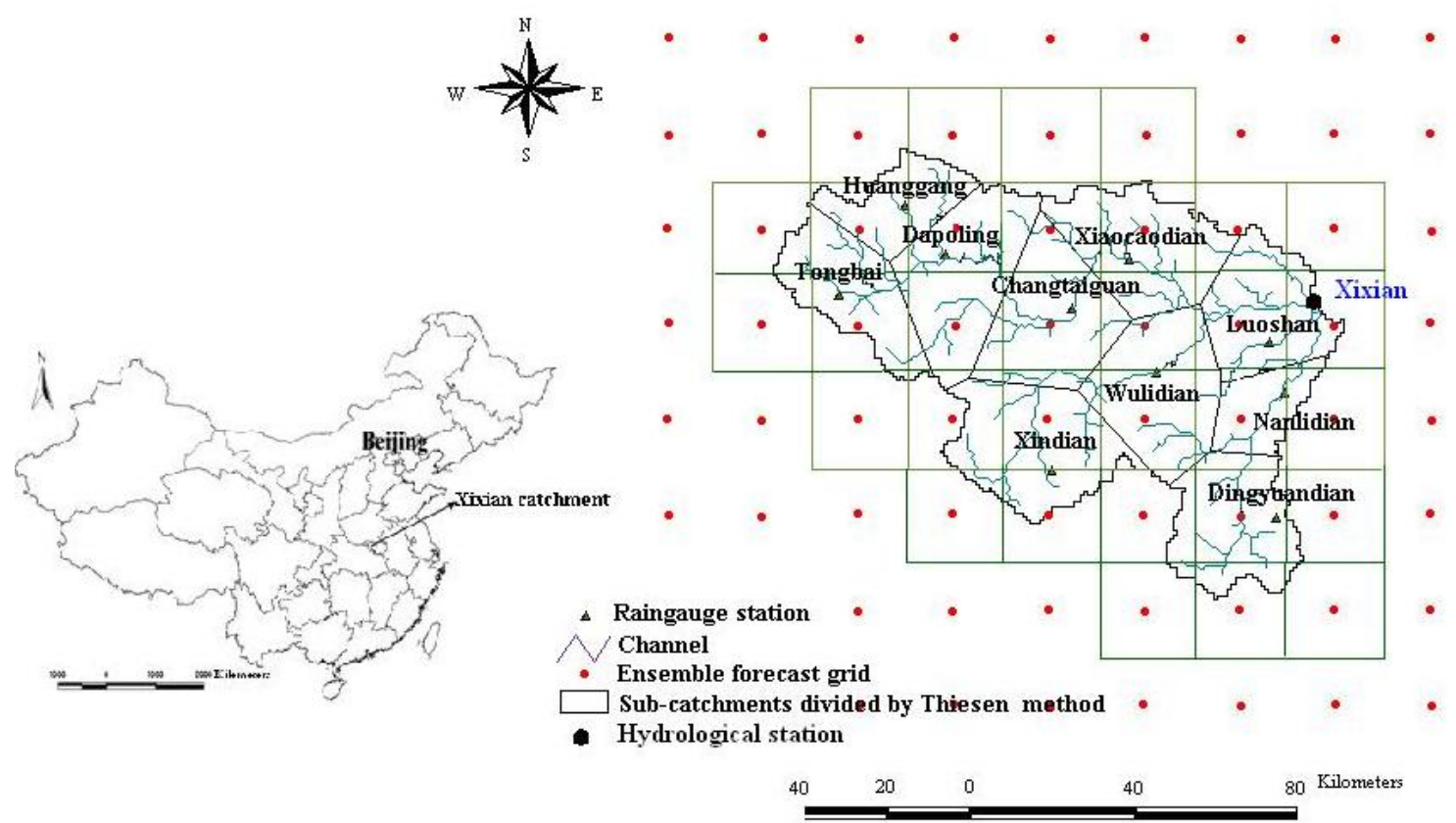

Figure 1. the location of Xixian catchment in China (left), and sketch of Xixian catchment (right

Observed hydro-meteorological data were obtained from China Meteorological Administration (CMA), and TIGGE data were obtained from TIGGE-China. When the study was conducted, EPS data was available from five centres in the TIGGE database with the majority delivering EPS from January 2007 onwards. The flood event taking place in July 2007 was selected as the flood event in the study area. The only five centres data is available in the TIGGE database during the studied flood occuring. Table. 1 lists the five weather centres and their numbers of ensemble forecasts.

Table 1. List of the meteorological forecast centres used in the case study

\begin{tabular}{|c|c|c|c|c|}
\hline Country/Region & Meteorological centre & $\begin{array}{c}\text { Centre } \\
\text { Abbreviation }\end{array}$ & Centre Code & $\begin{array}{l}\text { Ensemble } \\
\text { members }\end{array}$ \\
\hline Canada & Canadian Meteorological Centre & $\mathrm{CMC}$ & $\mathrm{BABJ}$ & $14+1$ \\
\hline China & China Meteorological administrator & CMA & CWAO & $14+1$ \\
\hline Europe & $\begin{array}{l}\text { European Centre for Medium-Range Weather } \\
\text { Forecasts }\end{array}$ & ECWMF & ECMF & $50+1$ \\
\hline UK & Meteorological Office & UKMO & EGRR & $23+1$ \\
\hline USA & National Centres for Environmental Prediction & NCEP & KWBC & $14+1$ \\
\hline
\end{tabular}




\section{The GMKHM model}

\subsection{Introduction of The GMKHM model}

The GMKHM model uses pixels for the DEM as the computational elements for rainfall-runoff modeling and each element consists of a water balance component and a cell-to-cell $\left(30^{\prime \prime} \times 30^{\prime \prime}\right)$ flow routing component. The evapotranspiration, runoff production, and runoff separation in every pixel are calculated by the related modules of original Xinanjiang model (Zhao, 1992; Zhao and Liu 1995) and the Green-Ampt infiltrationexcess model (Green and Apmt, 1911). The runoff yield of the computational element is composed of three components: surface, subsurface and groundwater, which are obtained from the value of tension water capacity and free water storage capacity of every cell. Outlet flow of each pixel to the outlet of the whole catchment is routed from cell to cell by using overland flow routing model based on kinematic wave theory with the computed order among the DEM grid cells. During the calculation of the runoff generation and runoff concentration in every computational element, the reinfiltration and influence of the river drainage network are taken into consideration (Band, 1986; Yao et al.,2009). The flow is partitioned into channel and downstream cell according to the channel inflow direction and channel outflow direction.

The application of DEM-based methods in this model provides catchment's basic features such as drainage network, flow length, catchment boundary and area for hydrologic simulations. Flow direction in every DEM cell was determined by using the D8 (deterministic eight neighbours) method (Fairfield and Leymarie, 1991), as a consequence, the matrix of grid cells containing a channel (channel-cells) and computation order of each cell in the DEM were also obtained.

\subsection{Calibration and Verification of The GMKHM model}

In order to establish the reliability and applicability of the GMKHM model in the Xixian catchment, the model was calibrated. In this study, 20 flood events from 1990 to 2008 that took place in the Xixian catchment were used for model calibration and verification at a 6-hour time step. Because radar-based precipitation data sets are not available in the study sites at present, in order to obtain the rainfall input of each cell and consider the spatial variability of precipitation and its effect on catchment response, the Xixian catchment was divided into 10 sub-catchments by using Thiessen polygon method. The smallest sub-catchment was $4.7 \%$ in the Xixian catchment. There is only one rain gauge in each sub-catchment by both division methods, so rainfall input of each cell can be obtained according to the gauged point value at the station in every sub-catchment. The GMKHM model is used with spatially uniform precipitation in every sub-catchment. According to the Accuracy Standard for Hydrological Forecasting in China (MWR (The Ministry of Water Resources of the People's Republic of China), 2000), the Nash Sutcliffe coefficient and the percent absolute error of peak flow, runoff volume and peak time are four important criteria to evaluate flood simulation and flood forecasting. In terms of peak flow, total runoff volume and peak time of each flood, the result of simulation or forecasting is satisfactory if the percent absolute peak error between the simulated and observed floods is less than $20 \%$, if absolute error between the simulated and observed floods is less than $3 \mathrm{~mm}$ or percent absolute runoff error less than $20 \%$ and if the difference in peak time is within a routing period or three hours, respectively.

In this paper, thirteen flood events were chosen to calibrate the GMKHM model parameters and seven flood events to verify the model in Xixian catchment. The results of verification are presented in Table 2; they are ordered by flood code of each flood event. The code of each flood event in column of Tables 2 stands for the start time of every flood event, for example, the event 20050820 was one that occurred on 20 August 2005. The statistical indices shown in Tables 2 include the relative peak flow error, relative runoff error, peak time error and Nash coefficient, i.e., the deterministic coefficient. The ratios of qualifying peak flow, flood runoff and peak time for the GMKHM model applied to the Xixian catchment are $100 \%, 90.0 \%$ and $95.0 \%$ respectively. The Nash coefficients of all of the events in Table 2 are greater or equal to 0.80 for the GMKHM model; the Nash coefficients of 12 floods are greater than 0.90 for the GMKHM model. The acceptable efficiency coefficients also indicate that the simulated flood hydrographs are conceptually reasonable for the model applied to the Xixian catchment. Tables 2 show that the simulation results of the GMKHM model can perform well in predicting flood runoff and outlet hydrographs. One factor may be that the effect of reinfiltration and drainage network on rainfall-runoff response considered by the gridded model is scale dependent; the response can be more accurately captured by the gridded model in larger catchments. Looking collectively at the calibrated and validated results for the Xixian catchment, the performances of the GMKHM model satisfy the first grade of flood forecasting calibration or validation (all of three ratios are more than $85 \%$ ) in terms of the standard established by MWR, China. These analyses confirm the forecast robustness and reliability of the proposed GMKHM model.

Table 2. Calibration and validation results of the GMKHM model in Xixian catchment

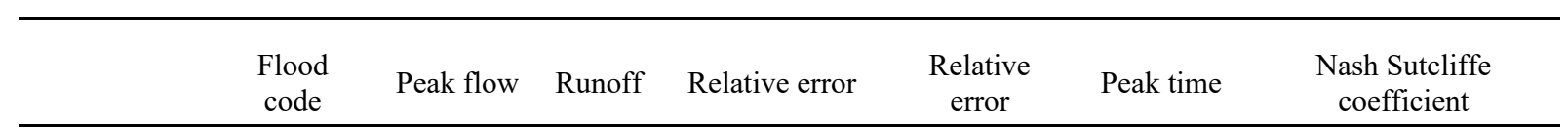




\begin{tabular}{|c|c|c|c|c|c|c|c|}
\hline & & $\left(\mathrm{m}^{3} / \mathrm{s}\right)$ & $(\mathrm{mm})$ & $\begin{array}{c}\text { of Peak flow } \\
(\%)\end{array}$ & $\begin{array}{l}\text { of runoff } \\
\qquad(\%)\end{array}$ & $\begin{array}{l}\text { error } \\
\text { (hour) }\end{array}$ & \\
\hline \multirow{13}{*}{ Calibration } & 19910517 & 1670 & 100.4 & 5.0 & 15.1 & -1 & 0.83 \\
\hline & 19910629 & 4410 & 187.4 & 12.0 & -0.5 & 0 & 0.95 \\
\hline & 19910801 & 4420 & 108.3 & 0.3 & -17.8 & 0 & 0.97 \\
\hline & 19910901 & 524 & 41.3 & 0.8 & 1.1 & -2 & 0.87 \\
\hline & 19950705 & 2300 & 48.7 & 6.1 & 1.2 & 0 & 0.96 \\
\hline & 19960619 & 4450 & 280.1 & 9.0 & -1.0 & 0 & 0.95 \\
\hline & 19980701 & 2510 & 60.9 & 0.4 & -26.6 & -1 & 0.89 \\
\hline & 19980803 & 4800 & 323 & -6.0 & -14.7 & 0 & 0.91 \\
\hline & 20000624 & 3150 & 145.8 & 5.1 & -10.3 & 0 & 0.89 \\
\hline & 20020621 & 5080 & 164.6 & 6.1 & -7.8 & 0 & 0.92 \\
\hline & 20030621 & 3900 & 143.9 & 11.5 & 5.2 & 0 & 0.96 \\
\hline & 20030716 & 3800 & 114.7 & -7.6 & -3.3 & 0 & 0.94 \\
\hline & 20040715 & 950 & 32.7 & -7.3 & 7.8 & 0 & 0.90 \\
\hline \multirow{8}{*}{ Validation } & 20040728 & 2520 & 66.8 & -8.7 & 1.4 & 1 & 0.84 \\
\hline & 20050623 & 1560 & 34.9 & -6.1 & 18.8 & 0 & 0.92 \\
\hline & 20050704 & 6000 & 159.8 & -14.5 & -7.1 & 0 & 0.98 \\
\hline & 20050820 & 3830 & 175.9 & 0.2 & -8.5 & -1 & 0.92 \\
\hline & 20050828 & 3830 & 123.1 & -5.4 & 10.0 & 1 & 0.92 \\
\hline & 20070711 & 4330 & 107.2 & 11.3 & -1.1 & 0 & 0.94 \\
\hline & 20080722 & 3700 & 85.2 & 6.1 & 1.2 & 1 & 0.91 \\
\hline & \multicolumn{3}{|c|}{ Absolute mean } & 6.5 & 8.0 & 0.35 & 0.92 \\
\hline
\end{tabular}

\section{Application and results}

The majority of the weather centres delivered global EPS data from January 2007 onwards. This study focused on one flood event that took place in July 2007 (Fig.2). The flood warning level at the Xixian station is $41.50 \mathrm{~m}$ and corresponds to a discharge of $4034 \mathrm{~m}^{3} / \mathrm{s}$. The warning level was reached at 0000 (UTC) on 15 July 2007 for the studied flood event and exceeded in the subsequent one day.

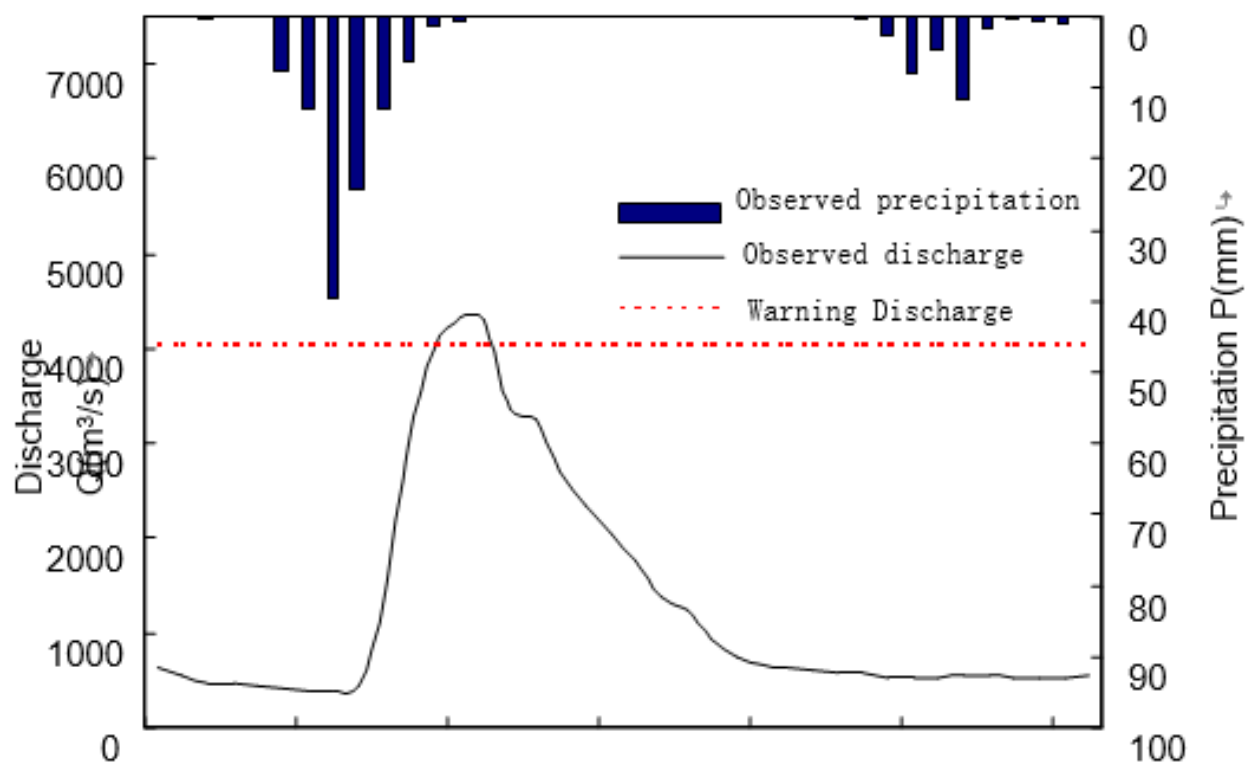

2007-7-12. 2007-7-13 2007-7-15 2007-7-16 2007-7-18 2007-7-19 2007-7-21

$\begin{array}{lllllll}0: 00 & 12: 00 & 0: 00 & 12: 00 & 0: 00 & 12: 00 & 0: 00\end{array}$

(UTC) Date

Figure 2. Observed 6-hourly precipitation and discharge at Xixian catchment 


\subsection{Precipitation input evaluation}

The precipitation forecasts $\boldsymbol{P}_{\boldsymbol{f}}$ were retrieved from five weather centres in the TIGGE archive, namely Canadian Meteorological Centre (CMC), China Meteorological Administration (CMA), European Centre for MediumRange Weather Forecasts (ECMWF), UK Met Office (UKMO), and National Centres of Environmental Prediction (NCEP). The forecasts of 11 July 2007 from NCEP were excluded from this study due to an error that occurred during data extraction. For the selected five centres, each provides one 'central' unperturbed analysis and a number of forecasts with perturbed initial conditions. All forecast members were assigned equal weights (Park et al., 2007). The consequent inference is based on the principle of equal probability of selection. The original medium-range forecasts are corrected in ca. $25 \times 25 \mathrm{~km}$ resolution (He et al, 2009; 2010). They were interpolated to areal averages of ten sub-catchments to be used as inputs for the GMKHM model. Buizza (2008) pointed out that consistency between forecasts issued on consecutive days is a desirable property of a forecasting system, therefore we examined the feature by visually comparing
$\boldsymbol{P}_{\boldsymbol{f}}$ of small, moderate and heavy precipitation with thresholds per day of $0.0 \sim 9.9 \mathrm{~mm}, 10 \sim 24.9 \mathrm{~mm}$, over $25 \mathrm{~mm}$ respectively. These thresholds are defined by the National Meteorological Centre of CMA. In this paper, the threat scores (TS) method (Zhao et al, 2010) was employed to evaluate the performance of the five weather centres and their grand ensemble. TS ranges from 0 to 1 , with 0 indicating no skill and 1 perfect.

Fig.3 (a-b) shows the dichotomous forecast verification of the three category precipitation obtained from five EPSs and grand ensemble over Xixian catchment. TS (Fig.3(a)) shows that the five EPSs and grand ensemble have diferent peformance. Scores of CMA, ECMWF and NCEP, ranged from 0.46 to 0.67 with TS and from 0.92 to 1.49 with bias score (B) with lead time ranging from 24 hours to 240 hours, is slightly better than that of CMC and UKMO for small precipitation. In the range of moderate precipitation, UKMO performs better than other 4 centres. Five EPSs all have the TS value below 0.30 for heavy precipitation, which indicated that these events were rarely captured. Grand ensemble has a slightly better TS value than CMA and CMC.

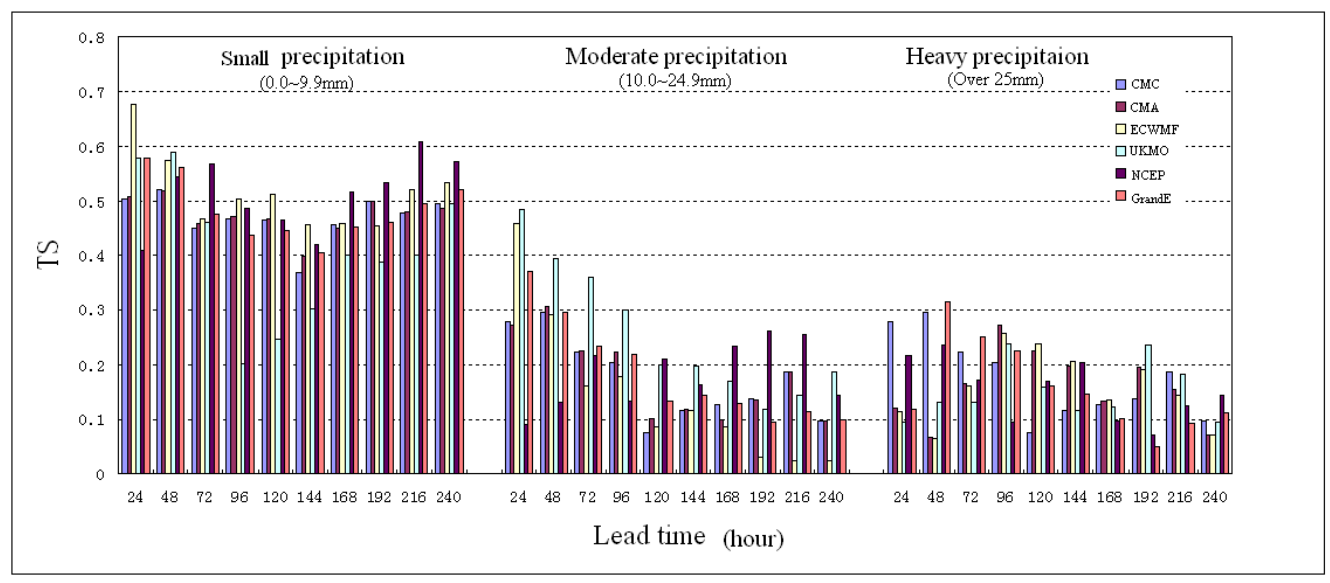

a. Threat Score

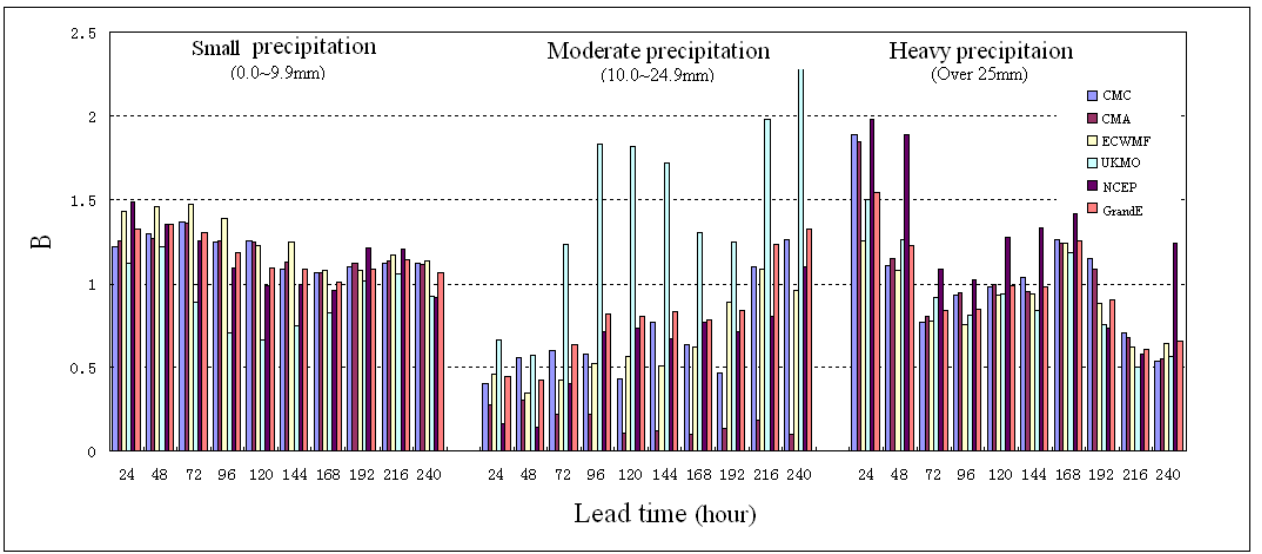

b Bias Error

Figure.3 Yes/no forecast verification of the three category precipitation obtained from CMC, CMA, ECWMF, UKMO, NCEP and their grand ensemble (GrandE) over the Xixian catchment 


\subsection{Discharge simulation}

Fig.4 shows the area mean $\boldsymbol{P}_{\boldsymbol{f}}$ issued at 12:00 (UTC) 11 July 2007 and resulting $\boldsymbol{Q}_{f}$ at the Xixian station using ECMWF. All ECMWF forecast members issued on 12 July 2007 displayed the best agreement for the rainfall event occurred on 13 July 2007. Similarly, the amount and timing of the rainfall between 13 July 2007 and 15 July 2007 were best forecasted with 2-day lead time, i.e. from 14 July 2007 to 16 July 2007. For lead times longer than two day, the 51 ECMWF forecast members demonstrated a fairly consistent signal representing an intensive rainfall event but one could not tell the exact date and time it was to occur as the spread of forecast members was rather large. For example, forecasts issued on 11 July 2007 indicated a large precipitation event would possibly occur on 14 July 2007 . Less than $10 \%$ of the forecast members predicted it was to occur on 15 July 2007. The situation improved on 13 July 2007 when most forecast members clustered closer to each other than on the previous day of issue (over 70\% members agreeing on 15 July 2007). Disagreements between probabilistic and single forecasts can be used as an indication of potentially low predictability (Buizza 2008) and vice versa. The progress of agreement amongst forecast members evolved from longer to shorter lead times demonstrates the EPS forecasts become more predictable as it is getting closer to the actual event. In comparison to the observed discharge, the ensemble of $\boldsymbol{Q}_{f}$ was underestimated by approximately $10-30 \%$ for all forecast members varying from day to day. In this study, $\boldsymbol{Q}_{50}$ is very comparable with the $\boldsymbol{Q}_{\text {sim-raingauge }}$ for ECWMF, and $\boldsymbol{Q}_{95}, \boldsymbol{Q}_{50}, \boldsymbol{Q}_{50}, \boldsymbol{Q}_{95}$ for CMC, CMA, UKMO, NCEP respectively

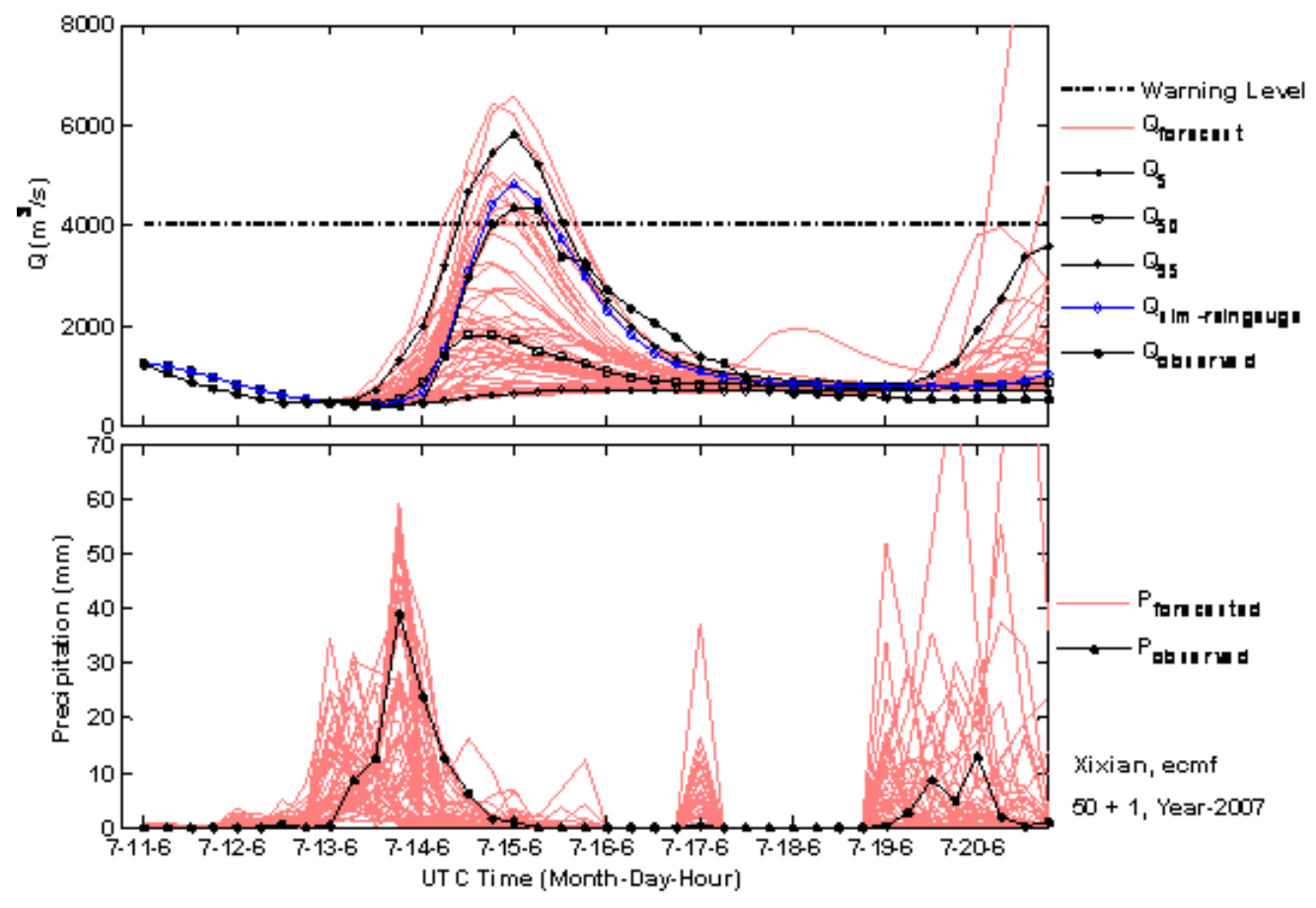

Figure 4 Ensemble precipitation forecasts issued on 11 July, 2007 by "ECWMF" (lower) and ensemble forecast discharges (upper) in comparison with observation.

The ensemble of $\boldsymbol{Q}_{f}$ was evaluated using a warning table, where observations were compared with simulations. The warning table shows the forecasts ability to predict the individual events. The studied flood event is well predicted by all centres with a few days in advance(see Fig.5 for warning level). The percentages correspond to the percentage of members higher than the alert threshold $\left(4034 \mathrm{~m}^{3} / \mathrm{s}\right)$. However, making use of multiple centres from the TIGGE archive did not always show a better performance than using a single EPS centre. This indicates grand ensemble does not necessarily lead to a better performance than a single EPS. Techniques for combining multiple centres should be investigated in the future. 


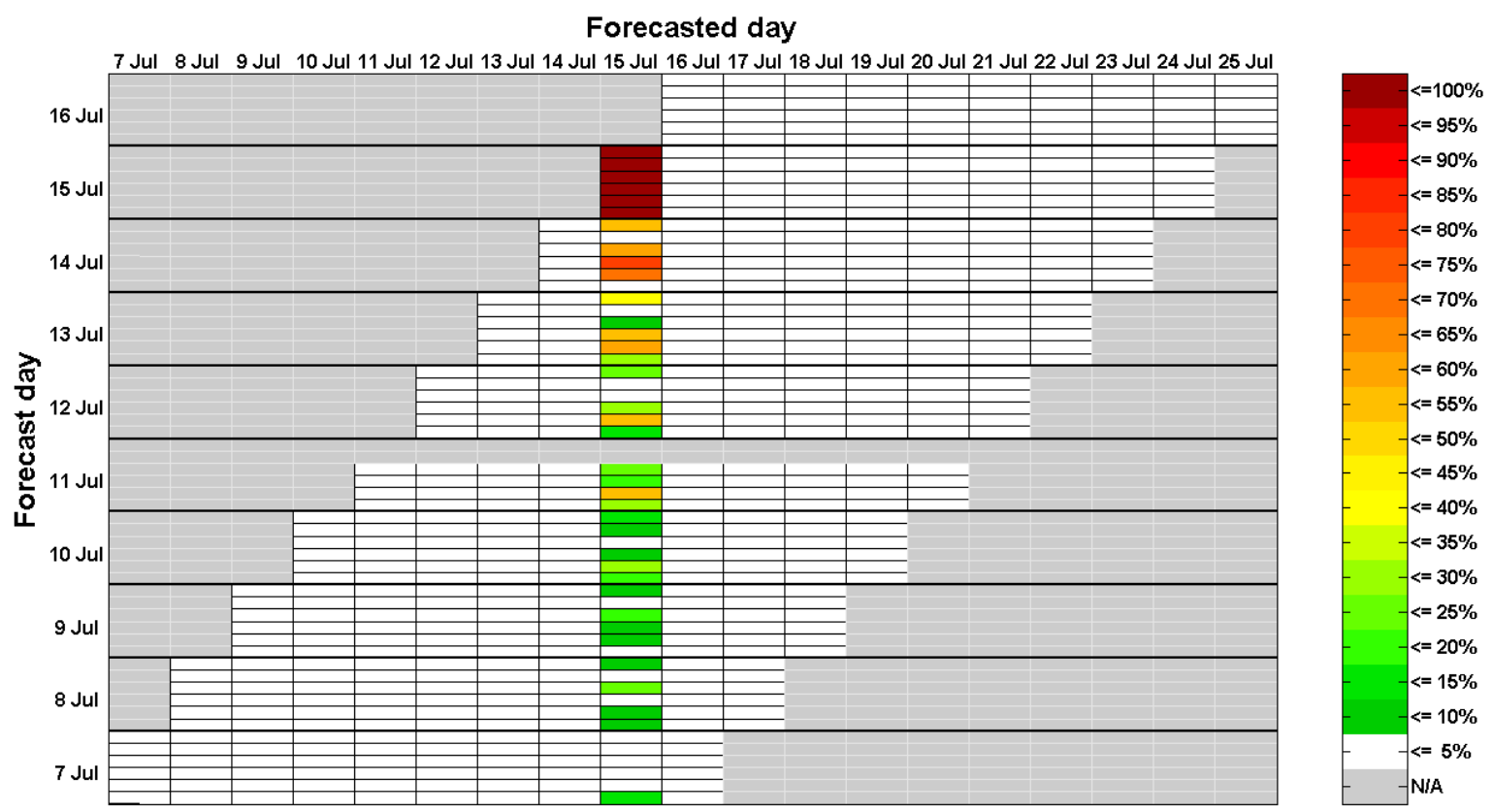

Figure 5 The warning table for the studied flood event. The six horizontal bars from bottom to top represent the five centers (CMC,

CMA, ECWMF, UKMO, NCEP), and the ensemble of the five forecast centers.

\section{Conclusion and outlook}

A coupled atmospheric-hydrologic flood forecast model driven by the TIGGE ensemble forecasts is set up to study the potential benefits of using the TIGGE database in flood forecasting in the upper reaches of Xixian catchment during the 2007 flood seasons. GMKHM model is applied for forecasting rainfall-runoff process. The results demonstrate (1) the Grid-Xinjiang model can perform well for flood simulation and forecasting in the Xixian catchment. (2) The TIGGE archive is a promising tool for issuing a fairly reliable warning as early as 10 days in advance with producing forecasts of discharge comparable with the observed discharge. The reliability of the forecast can be improved at longer leadtimes, which holds great benefit for flood management and preparedness.

Techniques to deal with multi-model forecasts need to be developed. In this study, the principle of equal probability of selection was applied. Multiple EPS inputs should be used with great caution as they have different error structures and can't be easily combined (Cloke and Pappenberger, 2009; He et al, 2010). Different weather forecasts may be assigned a different weight coefficient, which might improve the performance of the grand ensemble.

A spatial and temporal correction to the ensemble weather predictions to resolve discrepancies in the spatial distribution and timing should be developed for flood forecast. The precision of rainfall forecast affects an offset of the peak in term of timing and magnitude that led to the partial failure in early flood warning in hydrological forecasting.

\section{Acknowledgements}

This work was supported by the National Key Research and Development Program of China (Grants No. 2016YFC0402702), the National Natural Science Foundation of China (Grants No. 41775111,51509043), the National Key Research and Development Program of China (Grants No. 2016YFC0402702).

\section{References}

1. Band, L. E.. "Topographic partition of catchments with digital elevation models."Water Resour. Res., 22(1), 15-24.1986.

2. Bao, H. J. Coupling EPS-Hydrologic-Hydraulic Model for Flood Forecasting. Ph. D. Dissertation. Nanjing: Hohai University. (In Chinese), 2009.

3. Bao, H. J. Research on the Application of Flood Forecasting and Scheduling Model in the Catchment of Yishusi. M. E. Dissertation. Nanjing: Hohai University. (In Chinese), 2006.

4. Bao H.J. and Zhao L.N.. Application of a developed atmospheric-hydrologic-hydraulic flood forecasting model driven by TIGGE ensemble forecasts. Acta Meteor. Sinica, 2012, 26(1):93-102.

5. Bao H.J., Li Z.J.,Wang L.L.,et al. Flash flood forecasting method based on distributed hydrological models in a small basin and its application, Torrential Rain and Disasters. 2017,36(2):156-163.

6. Bao H.J., Wang L.L.,Zhang K, Li Z.J.. Application of a developed distributed hydrological model based on 
the mixed runoff generation model and 2-D kinematic wave flow routing model for better flood forecasting, Atmospheric Science Letters, 2017,18(7):284-293.

7. Buizza R. The value of probabilistic prediction.Atmospheric Science Letters Special Issue:HEPEX 2008,9:36-42

8. Cloke H. L., Pappenberger F. Evaluating forecasts for extreme events for hydrological applications: an approach for screening unfamiliar performance measures. Meteorological Applications, 15(1): 181-197. 2008.

9. Cloke H. L., Pappenberger F. Ensemble flood forecasting: A review. Journal of hydrology,375:613-626. 2009.

10. Cunge, K. A.. "On the subject of a flood propagation method (Muskingum Method)." $J$. Hydrau. Res., 7, 205-230.1969.

11. Demeritt, D. et al. Ensemble predictions and perceptions of risk, uncertainty, and error in flood forecasting. Environmental Hazards, 7(2): 115. 2007.

12. DKKV. Flood Risk Reduction in Germany. Lessons Learned from the 2002 Disaster in the Elbe Region. Summary of the Study. Deutsches Komitee fuer Katastrophen vorsorge (DKKV) (German Committee for Disaster Reduction). Publication 29e. Bonn, 2004.

13. Fairfield, J., and Leymarie, P. "Drainage networks from grid digital elevation models." Water Resour. Res., 27(5): 709-717. 1991.

14. Goswami M, OConnor K, Bhattarai K. Development of regionalisation procedures using a multi-model approach for flow simulation in an ungauged catchment. Journal of Hydrology 333 (24): 517-531. 2007.

15. He Y, F Wetterhall, H.L. Cloke, et al. Tracking the uncertainty in flood alerts driven by grand ensemble weather predictions, Meteorological Applications, Special Issue: Flood Forecasting and Warning, 16(1): 91 - 101. 2009.

16. He Y, F Wetterhall, Bao H J.,et al. Ensemble forecasting using TIGGE for the July-September 2008 floods in the Upper Huai catchment: a case study, Atmosphereric Science Letters.DOI:10.1002/as1.270. 2010.

17. Li, Z. J., Cheng, Y., and Xu, P. Z. Application of GISbased hydrological models in humid catchments. Water for Life: Surface and Ground Water Resources, Proceedings of the 15th APD-IAHR \& ISMH, 685690. Madras. 2006.

18. Wang, L. L., Li, Z. J., and Bao, H. J. Application of hydrological models based on DEM in the Yihe catchment. Journal of Hydrologic Engineering, 37(S1), 417-422. (in Chinese) . 2007.

19. Penning-Rowsell, E., Tunstall, S., Tapsell, S. and Parker, D., The benefits of flood warnings: Real but elusive, and politically significant. J. the Chart. Inst. Water Environ. Manage., 14: 7-14. 2000.

20. Park YY, Buizza R, Leutbecher M. TIGGE: preliminary results on comparing and combining ensembles. ECMWF TM 548, European Centre for Medium-Range Weather Forecasts (ECWMF), Reading, UK. 2007.

21. Parker, D. and Fordham, M., Evaluation of flood forecasting, warning and response systems in the European Union. Water Resour. Management, 10(279-302). 1996.

22. Pitt, M. Learning Lessons from the 2007 floods: An independent review by Sir Michael Pitt: interim report, London, UK., 2007.

23. Roulin E. Skill and relative economic value of medium-range hydro-logical ensemble predictions. Hydrology and Earth System Sciences Discussions 3: 1369-1406. 2006.

24. The Ministry of Water Resources of the People's Republic of China (MWR)."Standard for hydrological information and hydrological forecasting (SL 250-2000).'Hydraulic and Hydropower Publisher of China, Beijing, 18-21 (in Chinese). 2000 .

25. Van Berkom, F., van de Watering, C., de Gooijer, K. and Neher, A., Inventory of Flood Information Systems in Europe - a study of available systems in Western-, Central- and Eastern Europe, INTERREG IIIC Network Flood Awareness and Prevention Policy in Border Areas' (FLAPP), the Netherlands. 2007.

26. Yao, C., Li, Z. J., Bao, H. J., and Yu, Z. B. Application of a developed Grid-Xin'anjiang model to Chinese catchments for flood forecasting purpose. Journal of Hydrologic Engineering, 14(9), 923-934. [doi:10.1061/(ASCE)HE.1943-5584.0000067] .2009.

27. Zhao L.N., Wu H., Tian F. Y,,et al.2010: Assessment of Probabilistic Precipitaiton Forecasts for HUAIhe Catchment Using TIGGE Data ,Meteor.Mon.,36(7):133-142 (in chinese)

28. Zhao, R. J. The Xin'anjiang model applied in China. Journal of Hydrology, 135(1-4), 371-381. [doi: 10.1016/0022-1694(92)90096-E] . 1992.

29. Zhao R, Liu X. The Xinanjiang model. In Computer Models of Catchment Hydrology, Singh VP (eds). Water rsources Pubns. 1995. 